\title{
Curaduría transatlántica: cómo la digitalización de las colecciones promueve la colaboración
}

\section{Transatlantic Curation: How Digitizing Collections Promotes Collaboration}

\section{Claudia Zehrt ${ }^{\mathrm{a}}$ y Ana Somohano Eres ${ }^{\mathrm{b}}$}

${ }^{a}$ University College London y British Museum, Londres; c.zehrt@ucl.ac.uk ${ }^{\mathrm{b}}$ Universidad Nacional Autónoma de México; ana.somohano.eres@gmail.com

\section{Resumen}

Gracias al desarrollo de las tecnologías digitales en el ámbito de los museos $y$ del patrimonio, los curadores y profesionales de distintas partes del mundo cuentan con nuevos medios para la curaduría, la colaboración y el desarrollo de nuevas metodologías, así como una visión crítica sobre la propagación y la utilidad de las herramientas digitales y los métodos con los que se abordan. Algunas de las problemáticas que surgen en torno a la digitalización en los museos incluyen el copyright y la propiedad de los objetos, la equidad en el acceso a los recursos digitales y al uso de Internet, el lenguaje empleado en la descripción de las piezas y en la recolección de datos, la influencia institucional y/o externa sobre las prioridades y orden en la digitalización de las colecciones, las diferencias en la manera de emprender los proyectos en distintas partes del mundo. El objetivo de esta contribución será abrir la discusión sobre algunos de estos aspectos teniendo en cuenta tanto la experiencia del proyecto de digitalización de la Colección Maudslay (consistente en su mayoría de reproducciones y fotografías de monumentos del área maya realizadas en el $s$. XIX) en el Museo Británico, así como las oportunidades para la colaboración e intercambio que este proyecto abrió con colegas y comunidades de América Central.

Palabras clave: Digitalización de colecciones, réplicas en 3D, curaduría digital, arqueología maya, curaduría colaborativa.

\footnotetext{
Abstract

The advent of digital technologies in museums and cultural heritage offers curators and heritage professionals worldwide novel approaches to curation and collaboration, facilitates the development of new methodologies, as well
} 
as elicits critical insight into the spread and effectiveness of digital tools and the methods with which they are approached. Some of the problems that arise around digitisation in museums include questions about copyright and intellectual property; the equality of access to digital resources and the internet; the language employed to describe objects and in data collection; the internal and/or external influences on priorities and sequence of collection digitisation; and the differences in the way projects are undertaken in different parts of the world. The aim of this contribution is to encourage discussion about some of these aspects, based on the experience of the digitisation of the Maudslay Collection at the British Museum (mainly consisting of casts and photographic negatives of monuments from the Maya area made at the end of the 19th century), as well as the opportunities created by this project to collaborate and interchange ideas and knowledge with colleagues and communities in Central America.

Keywords: Digitisation of museum collections, 3D models, digital curation, Maya archaeology, co-curation 


\section{Introducción}

El Proyecto Google Maya surgió como una colaboración entre el Museo Británico y Google Arts \& Culture para digitalizar y promover el estudio de la Colección Maudslay resguardada en el Museo Británico. La digitalización de la colección promovió diversas oportunidades de colaboración con distintas instituciones de diversos países y con personas locales, lo que enriqueció el conocimiento generado a partir de los objetos.

El objetivo de este trabajo es analizar cómo la digitalización de la colección promovió estas colaboraciones, así como reflexionar sobre qué limitaciones encontramos en el proceso, de modo que otros proyectos similares puedan considerarlas en el futuro. Para ello, comenzamos presentando el Proyecto Google Maya, para luego exponer el carácter de las colaboraciones que se generaron y cómo la digitalización impulsó el trabajo multicolaborativo, presentando dos estudios de caso relevantes. A continuación, nos referimos a algunas de las dificultades que surgieron en el proceso y, para finalizar, nuestras conclusiones resaltan la importancia, beneficios y potenciales de los proyectos de digitalización, así como ciertas medidas que podríamos haber tomado para evitar algunos de los problemas que se presentaron.

\section{EI Proyecto Google Maya del Museo Británico}

Entre 2016 y 2020 se llevó a cabo el Proyecto Google Maya (Google Maya Project) del Museo Británico, orientado principalmente a la digitalización y difusión de la Colección Maudslay resguardada en esta misma institución. La Colección Maudslay está compuesta por distintos objetos derivados de la extensa documentación que el explorador británico Alfred Maudslay realizó en diversos sitios arqueológicos del área maya a finales del siglo XIX: unos 800 negativos fotográficos en placa de vidrio, unas 500 réplicas de yeso de monumentos, algunos de los moldes realizados para efectuar estas últimas (entre 400 y 900 piezas por monumento, además de calcos de papel), y un archivo documental de aproximadamente 1000 páginas que incluye algunas de las notas y diarios de campo del viajero victoriano, así como bocetos de sus colaboradores y borradores de publicaciones.

Entre 1881 y 1894 Alfred Maudslay realizó hasta ocho viajes a Centroamérica, visitando un importante número de sitios arqueológicos mayas, entre los que destacan Quiriguá, Copán, Tikal, Yaxchilán, Iximché, Ixkun y Chichén Itzá. Realizó las más incipientes excavaciones de algunos de estos sitios, efectuando una importante labor documental utilizando las más novedosas técnicas fotográficas y de realización de réplicas monumentales del momento. Esta documentación también incluyó algunos mapas muy detallados. ${ }^{1}$

Los materiales resultados de estas investigaciones (negativos, moldes y piezas arqueológicas) fueron enviados por el investigador a Inglaterra y la mayoría de estos llegaron a formar parte de la colección del Museo Británico en los primeras décadas del siglo XX (otras instituciones,

\footnotetext{
${ }^{1}$ Para profundizar en los logros personales y profesionales de Alfred Maudslay, el lector puede consultar su documentada biografía realizada por el arqueólogo Ian Graham (Graham, 2002).
} 
como el Museo Victoria \& Albert, la Royal Geographical Society, el Royal Anthropological Institute y el Museo de Arqueologia e Antropologia Cambridge, también cuentan con objetos o documentos de Maudslay en sus colecciones). Con el cambio de siglo se realizó, además, una magna enciclopedia de historia natural de México y Centroamérica (Godman and Salvin,1879-1915), que incluyó un apéndice de cuatro volúmenes de temática arqueológica elaborados por Alfred Maudslay (Maudslay, 1889-1902: Vol. I-IV), incluyendo gran parte de las fotografías y dibujos.

El espíritu explorador de Alfred Maudslay estaba en gran medida incentivado por su convencimiento de que una buena documentación de los monumentos mayas habría de impulsar el desciframiento de la escritura maya. ${ }^{2}$ Esta misma visión inspiró en 2016 la creación del Proyecto Google Maya en el Museo Británico, motivada por la convicción de la utilidad de los documentos de Maudslay para la comprensión de la cultura maya tanto por parte de la comunidad académica como por parte del público general. ${ }^{3}$ Coincidiendo con los planes para el traslado de parte de la colección del museo, incluidos los moldes y yesos de la Colección Maudslay, a las nuevas bodegas del museo (BM-Arc, s.f.; The Art Newspaper, 2019), se planteó la posibilidad de realizar la digitalización de la Colección Maudslay, con el fin de acercarla a los especialistas y al público, tanto dentro del país como fuera de él. Esto también permitiría acercar la colección a un público para el que esta es particularmente significativa, el público centroamericano, donde se desarrolló la cultura maya antes de la llegada de los europeos y donde Maudslay había estado realizando sus exploraciones. De este modo, la labor del explorador victoriano, que había utilizado la tecnología más novedosa en su época para documentar los restos arqueológicos mayas, inspiró el proceder del Proyecto Google Maya, que trazó el objetivo de aplicar los avances tecnológicos más recientes para la documentación de la Colección Maudslay, al tiempo que realizaba labores de conservación y contextualización de la colección.

El equipo del proyecto, vinculado al Departamento de América del Museo Británico, estuvo conformado por el director del departamento, Jago Cooper, y por dos curadores. ${ }^{4}$ Para la digitalización se contó con el apoyo de Google Arts \& Culture, principalmente financiero, quien proporcionó además la plataforma digital para albergar la colección y equipamiento para digitalización. Google Arts \& Culture es una iniciativa del Google Cultural Institute que alberga material artístico y cultural digital producto de su colaboración con instituciones culturales, sin ánimo de lucro.

\footnotetext{
2 Efectivamente, un siglo después sus fotografias y réplicas jugaron un importante papel en el impulso epigráfico que llevó al desciframiento de la cultura maya en las últimas décadas del siglo XX.

${ }^{3}$ La importancia de la colección para la investigación sobre los antiguos mayas ya era conocida desde antes del comienzo del proyecto. En varias ocasiones se intentó facilitar el acceso a las réplicas y diversos especialistas y académicos habían estudiado la colección (por ejemplo, Matthews 1999). No obstante, el desarrollo del Proyecto Google Maya supuso un giro en el intento de hacer un estudio integral de la colección y ponerla a disposición de un público más amplio.

4 Estas tres personas conformaban el equipo del proyecto. No obstante, otros especialistas fueron contratados de manera puntual para colaborar con la curaduría o con la digitalización y el proyecto también contó ocasionalmente con la participación de otros trabajadores del Museo Británico.
} 
Uno de los desafíos de la Colección Maudslay, en términos de digitalización, pero también de conservación y almacenamiento, es la diversidad de materiales de la colección: cuenta con negativos en placa de vidrio y documentos en papel (objetos 2D), pero también moldes y réplicas de yeso (objetos $3 \mathrm{D}$ ). Especialmente con las réplicas, el proyecto trató de tener en cuenta la idea original de Maudslay: que la forma más útil de transmitir todos los detalles de las intrincadas tallas de la escritura jeroglífica maya no era a través de dibujos y fotografías bidimensionales, sino de tres dimensiones, una copia fiel del original (Maudslay 1889-1902, Vol. I Text).

Con eso en mente, el proyecto siguió dos vías diferentes, pero paralelas, para la digitalización de la colección. Las réplicas de yeso se digitalizaron en 3D utilizando un escáner de luz estructurada Artec Eva; como este dispositivo es portátil, le brindó al equipo las mejores oportunidades para escanear las réplicas en el entorno de la bodega, muchas veces estrecho y mal iluminado. También se probó la fotogrametría, aunque finalmente el Artec Eva resultó ser más práctico y eficiente para este caso en particular. Los negativos en placa de vidrio, las diapositivas y los materiales de papel (tanto publicados como inéditos) se digitalizaron con una "Estación de digitalización", el DT Atom. Esta estación se instaló en el Museo Británico por unos meses, cedida por Google Arts \& Culture y operada por personal del museo. El DT Atom permitió al equipo crear imágenes de alta resolución de los negativos de la placa de vidrio, los diarios de campo y otros materiales.

Como ya mencionamos, uno de los principales objetivos asociados a la digitalización de la colección era facilitar que estos materiales estuvieran ampliamente disponibles para todo el mundo. Al inicio del proyecto, tanto el sitio web del Museo Británico como la base de datos para uso interno de la institución eran bastante antiguos en términos de capacidades tecnológicas. Potencialmente, tener diferentes tipos de datos (fotos, escaneos 3D, materiales de archivo, etc.) en diferentes ubicaciones digitales o en diferentes niveles de una base de datos dificultaría la presentación de la colección como un conjunto coherente y que respetara la materialidad de los objetos.

Como parte del financiamiento y la participación de Google Arts \& Culture, el resultado del proyecto se desarrolló y presentó dentro de su plataforma. En nuestro caso, se diseñaron dos páginas web albergadas dentro de su plataforma, la primera publicada tras el primer año de proyecto, en la que se presenta la sección de la colección Maudslay relacionada con Guatemala (Google Maya Project, 2017), y la segunda, lanzada dos años más tarde, para la parte vinculada con México (Google Maya Project, 2019). Estos sitios web no sólo resguardan la colección digital, sino que la contextualizan presentando material complementario, curado por el proyecto.

\section{Un proyecto digital, colaborativo e internacional}

El Proyecto Google Maya nació como una iniciativa del Museo Británico y de su asociación con Google Arts \& Culture. Sin embargo, a lo largo de tres años de proyecto se fue 
configurando, a pesar de que no se había planteado en sus inicios como tal, como un proyecto multicolaborativo que contó con la participación de numerosas instituciones y personas tanto en Europa como en los dos países americanos relacionados con la colección, Guatemala y México. Por lo tanto, aunque el equipo estaba conformado por un director de proyecto y dos curadores del Museo Británico, la curaduría del proyecto se enriqueció de los aportes y conocimiento generados a ambos lados del Atlántico.

La principal colaboración del proyecto fue, como ya se ha indicado, con Google Arts \& Culture. Google Arts \& Culture no sólo aportó la financiación para poder elaborar un proyecto tan demandante como puede resultar una iniciativa de digitalización de colecciones, sino que también contribuyó proporcionando en préstamo tecnología para la digitalización a la que es difícil acceder (por ejemplo, la estación DT Atom) y facilitó la plataforma digital donde albergar la colección. Igualmente, contribuyó con personal cualificado en tecnologías digitales, quien realizó la fotogrametría del sitio arqueológico de Palenque, México, y generó a partir de ella un modelo 3D, que se usó, entre otras cosas, para un recorrido en realidad virtual (RV) y realidad aumentada (RA).

Sin embargo, para el proyecto fueron muy significativas las colaboraciones establecidas en Guatemala y México. Como países que albergaron el desarrollo de la cultura maya y donde residen un significativo número de mayas hoy en día, era esencial contar con su participación. De este modo, en ambos países se tejieron conexiones con instituciones y personas del lugar: instituciones culturales, museos locales y comunitarios, proyectos arqueológicos, artistas, activistas, y proyectos sociales y culturales. Todas ellas contribuyeron en mayor o menor medida al proyecto y al resultado final.

Finalmente, el proyecto contó también con la colaboración de varios académicos y expertos en la cultura maya. Algunos de ellos sugirieron mejoras al trabajo realizado, otros tomaron un rol más activo en la generación de contenidos en las páginas web, contribuyendo así a la contextualización de la colección.

Si bien la digitalización de una colección de museo no es necesaria para poder establecer un proyecto multicolaborativo, podríamos afirmar que la elaboración de nexos y la participación de las distintas partes involucradas se vio facilitada por esta digitalización.

En primer lugar, el hecho de poder contar con el material en línea facilitó el acceso a la colección a los colaboradores, abaratando los costes, los tiempos, y ahorrando los complicados trámites burocráticos que supone poderla visitar en bodegas, sobre todo para los colegas latinoamericanos. La digitalización en 3D de las réplicas de yeso permitió acceder a elementos que las tradicionales fotografías impiden, posibilitando de esa manera la apreciación de los objetos en su forma tridimensional. Sin embargo, las digitalizaciones no sólo fueron una forma alternativa de acceder a los objetos originales: el tamaño y peso de las réplicas hace que se olvide que son partes de monumentos más grandes, los modelos $3 \mathrm{D}$ permitieron ensamblar las distintas partes en un todo y favorecieron su movilidad en la pantalla (por ejemplo, permitieron apreciar detalles que en el original quedan a $5 \mathrm{o} 7 \mathrm{~m}$. de altura). 
En relación con las placas fotográficas, la digitalización en altísima calidad a través de la estación DT Atom permite una ampliación de la imagen escaneada de hasta un $900 \%$ y con eso proporcionó el acceso a detalles hasta ahora nunca apreciados (ver Fig. 1). Asimismo, la digitalización facilitó el acceso a partes de la colección que son sumamente frágiles, como los moldes de papel, promoviendo su conservación.

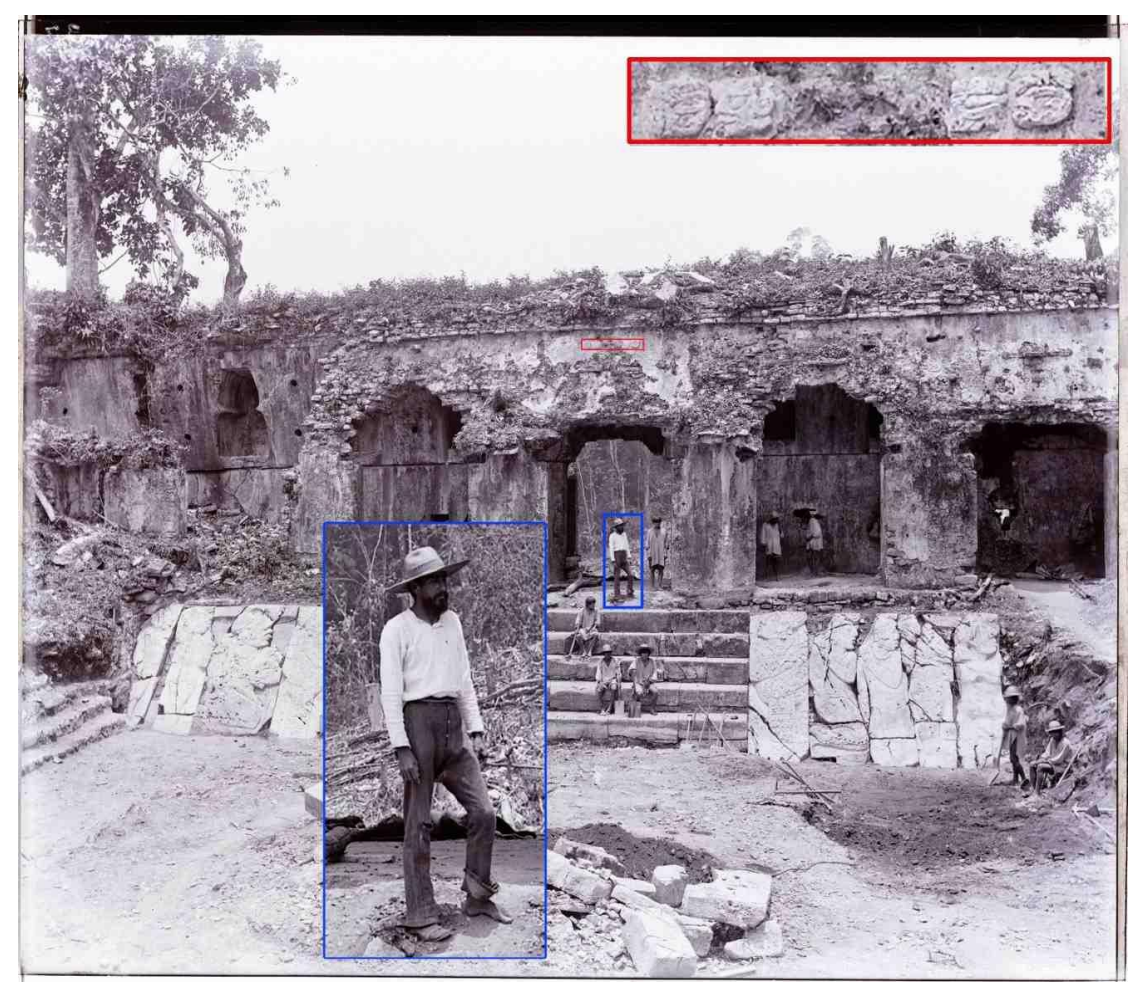

Fig. 1 Ejemplo de un negativo de la Colección Maudslay escaneado mediante la estación DT Atom. Se pueden apreciar detalles como los glifos en estuco en la arquitectura o un colaborador. (ㄷ British Museum)

Por todo ello, se puede decir que la digitalización de la Colección Maudslay proporcionó a los expertos un material con el que poder avanzar en sus investigaciones. Igualmente, permitió que accedieran a la colección ciertos colectivos locales para los que era significativa y para los que viajar a Londres puede resultar sumamente complicado. Esto hizo que se multiplicaran las narrativas generadas a partir de la colección. El proyecto cree firmemente que esta multiplicación de narrativas enriquece en gran medida el valor de la colección y quiso incluirlas en la contextualización y curaduría que se realizó de ella; las páginas web del proyecto recogen contribuciones de varios de nuestros colaboradores. De este modo, la curaduría digital contribuyó a una co-creación del conocimiento que se ve reflejado en el resultado final albergado en la plataforma.

Esta co-creación de conocimiento no sólo permitió dar voz a ciertas instituciones y personas más allá del equipo curatorial del Museo Británico, sino que permitió aumentar la visibilidad 
en la red de ciertas iniciativas locales cuyos medios y posibilidades son más reducidos. Consideramos que esta mayor visibilidad puede contribuir a que estos colectivos consigan darse a conocer en un mayor número de círculos y poder así ampliar sus campos de actuación.

La digitalización de la colección y la asociación con Google Arts \& Culture no solo nos facilitaron las páginas webs donde se realizó la curaduría, posibilitando una mayor visibilidad de la colección y que esta alcanzará a un público más amplio, sino que también nos permitieron el uso de diversos medios digitales con los que pudimos multiplicar las formas de presentación y contextualización de la colección y adaptarla a los distintos tipos de públicos. Tuvimos a nuestra disposición desde el tradicional Youtube, a los menos conocidos Google Poly (donde se guardaron las digitalizaciones 3D y se crearon los recorridos virtuales), Google StreetView y Google Earth Voyager (para localizar y después contextualizar el lugar donde Maudslay había tomado sus fotografías) o Google Expeditions (una herramienta educativa que permite acercar la divulgación cultural en las escuelas).

Finalmente, y como veremos a continuación, la digitalización de la colección contribuyó a la exploración de novedosas tecnologías que potencializaran las posibilidades de los objetos que la integran en la conservación de la arqueología maya, proporcionando al proyecto de elementos con los que contribuir al trabajo de los colaboradores

A pesar de que estamos convencidas de que la digitalización de la colección fomentó la colaboración entre distintas partes interesadas, enriqueciendo el proyecto, lo cierto es que también encontramos diversas dificultades y objetivos que no cumplimos del todo satisfactoriamente a lo largo de su duración. Nuestro propósito en lo que resta del texto es exponer críticamente algunos de estos aspectos, pues creemos que son elementos a tener en cuenta a la hora de emprender un proyecto digital y multicolaborativo. Por razones de espacio, sería imposible abordar todos ellos; por tanto, nos detendremos especialmente en dos de las colaboraciones que llevamos a cabo y que a nuestro parecer son las que mejor ilustran varios de estos aspectos: los casos de la Coordinación Nacional de Conservación del Patrimonio Cultural (CNCPC) de México, integrada al Instituto Nacional de Antropología e Historia, y el caso de la Radio Yúuyum, un proyecto local de comunicación en lengua maya yucateco. Empero, cuando sea necesario recurriremos también a otros casos de colaboración.

En 2018, la visita de los miembros del Proyecto Google Maya a Palenque, México, permitió a los curadores entrar en contacto con algunos miembros del equipo de conservación del sitio arqueológico, adscrito al CNCPC: la arqueóloga Martha Cuevas García y la restauradora Luz de Lourdes Herbert Pesquera. Ambas habían conformado un proyecto de registro de los monumentos escultóricos de la ciudad, interesándose en las fotografías que Maudslay había tomado en 1891, algunas de las primeras imágenes tomadas de Palenque y que mostraban elementos de la escultura hoy perdidos o descontextualizados. La digitalización de las fotografías en alta resolución a través del DT Atom les permitió una nueva mirada a las imágenes pues, como hemos comentado, daba acceso a detalles de las fotografías que antes eran imperceptibles. En concreto, los epigrafistas adscritos al proyecto de la CNCPC, Ángel Sánchez Gamboa y Yuri Polyukhovich, mostraron gran interés por analizar el registro de la 
Escalera Jeroglífica, la cual ha sufrido un gran deterioro desde el momento que fue fotografiada por Maudslay. Las digitalizaciones de las réplicas de la escalera del Museo Británico y las fotografías les proporcionaron el material para realizar una nueva lectura del texto jeroglífico de la escalera (Sánchez et al., 2020). Sin embargo, más allá del aporte científico, el daño de la escalera jeroglífica urgía encontrar una solución para su conservación. Se presentó la posibilidad de generar una réplica a partir de las réplicas en yeso de Maudslay que, al haberse realizado hace 130 años, todavía guardaba gran detalle. La división de la réplica de la escalera jeroglífica en 13 objetos distintos y la fragilidad de los objetos hubieran hecho esa empresa imposible hasta entonces; la versión digital en 3D de la escalera, no obstante, permitía ensamblar las piezas y realizar una réplica sin necesidad de tocar los objetos originales de Maudslay (ver Fig. 2). A partir de la digitalización, la empresa Pangolin, Reino Unido, realizó una nueva réplica en piedra ajustándose a las necesidades del equipo de conservación (Herbert et al., en prensa) y esta fue donada al INAH en noviembre de 2019. Como parte de nuestra colaboración, además, los epigrafistas Ángel Sánchez y Yuri Polyukhovich elaboraron una exposición en línea dentro de la página web del Proyecto Google Maya con sus nuevas interpretaciones del texto de la escalera y explicando cómo la Colección Maudslay había contribuido a ellas (Sánchez y Polyukhovich, s.f.).

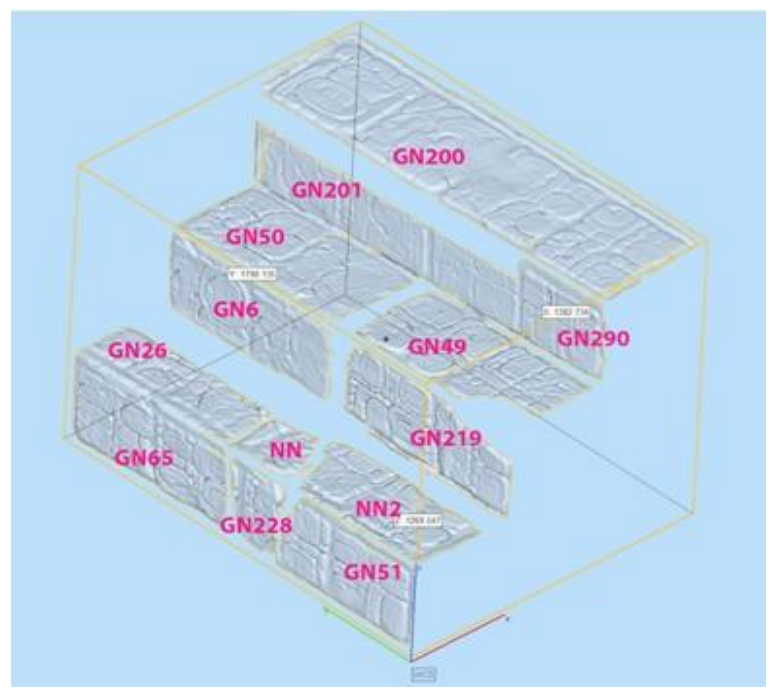

Fig. 2 Réplicas de yeso de la EJ de Palenque reensambladas digitalmente

Por su parte, Radio Yúuyum es una estación de radio comunitaria en maya yucateco constituida por el trabajo voluntario de varias personas que hablan esa lengua, con sede en Mérida, México. Para el Proyecto Google Maya era importante incluir en la página web de México algunas iniciativas para la divulgación de la cultura maya actual. En nuestra visita a Yucatán en febrero de 2019 tuvimos la oportunidad de entrar en contacto con este colectivo y, posteriormente, visitar la sede de la radio y contemplar su trabajo. Los miembros de Radio Yúuyum decidieron colaborar con nosotros; se realizó una entrevista en la que explicaban la labor de la radio, la cual fue colgada en la página web (Somohano Eres y Zehrt, s.f.). Al 
mismo tiempo, nos plantearon las dificultades para la difusión de una radio comunitaria debido a la escasez de recursos económicos, por lo que el proyecto se comprometió a suplir algunos de los equipos que eran necesarios.

\section{Un proyecto, demasiados enfoques}

Si bien la digitalización de la colección y su presentación dentro de la plataforma de Google Arts \& Culture nos abrió diversas posibilidades de colaboración, muchas veces los ánimos de cooperación están cargados de buenas intenciones y es a través del trabajo conjunto que van surgiendo dificultades que es necesario solventar.

El proyecto se benefició de la participación de varias instituciones que provenían de distintos países, principalmente Reino Unido, Guatemala y México. Sin embargo, no debemos olvidar que cada una de las partes colaborativas está sujeta a diferentes legislaciones y posibilidades institucionales. Un ejemplo claro de ello son los derechos de copyright y permisos de reproducción de imagen. Ya algunos autores han hablado de cómo la reproducción digital de imágenes en la red complejiza los derechos sobre las imágenes de los objetos contenidos en los museos (Pagel, 2015; Garvin, 2019; Schötz, 2020). Si bien el Museo Británico conservó los derechos de copyright de las imágenes de la plataforma, deben mencionarse las precauciones institucionales a perder el control sobre la narrativa de sus objetos, lo que también significaría que el museo estaría en peligro en su posición tradicional como puerta de entrada al conocimiento (ver Lynch, 2001; Garvin, 2019). Además, a pesar de haber conservado el copyright, no es seguro que el público que accede a ellas sepa siempre a quién pertenecen las imágenes, ya que no es tan fácil acceder a esta información dentro de la plataforma y, una vez colgadas en ella, todo el mundo puede reproducir las imágenes, complicando su identificación con el Museo Británico. El problema del copyright aumenta si se tiene en cuenta que nuestros colaboradores, algunos de los cuales contribuyen a la página, provienen de otros países. Los autores de la exhibición de la escalera jeroglífica, por ejemplo, tuvieron que limitarse al uso de imágenes del Museo Británico y del Proyecto Google Maya, limitando así la información que podían dar, para evitar un conflicto de reconocimiento del copyright. Igualmente, hay que tener en cuenta que las legislaciones de estos países en cuanto a los derechos de imagen son diferentes. Si bien algunas de las fotografías de los sitios arqueológicos mexicanos fueron realizadas por los mismos curadores del proyecto y, por tanto, el proyecto ostenta los derechos intelectuales sobre ellas, el gobierno mexicano a través del INAH conserva los derechos de imagen sobre estos. Esto supuso una fuerte carga económica para el proyecto, que tuvo que pagar para poder utilizarlas, así como limitaciones para los propios trabajadores del INAH, algunos de los cuales se encontraban colaborando con nosotros.

Así como existen diferencias legales entre países, también tuvimos que enfrentarnos a diferencias en los modos de trabajar entre las distintas instituciones y colaboradores. Cada uno de los participantes tenía sus propios objetivos a la hora de participar en el proyecto. Por ejemplo, en la colaboración con el equipo de conservación de Palenque, las colaboradoras de 
la CNCPC estaban más enfocadas en las posibilidades de conservación de la escalera que les brindaba la nueva tecnología, mientras que el Proyecto Google Maya estaba centrado en cómo podría el proyecto de conservación contribuir a la página web. Aunque podríamos decir que felizmente se lograron ambos objetivos, sí supuso un esfuerzo mayor por ambas partes para conseguir que todos los implicados salieran satisfechos. La colaboración con Radio Yúuyum es un claro ejemplo de cómo pueden malinterpretarse las necesidades de otro colectivo. Los curadores del Proyecto Google Maya creímos erróneamente, a pesar de nuestras buenas intenciones, que lo que los miembros de la radio comunitaria necesitaban era visibilidad, cuando ellos primero necesitaban los medios técnicos para poder realizar una labor que difundir.

Aparte de los diferentes objetivos a cumplir por parte de los colaboradores, también hubo que adaptarse a los diferentes tiempos institucionales: la labor de los colaboradores implicaba siempre trámites burocráticos dentro de sus propias instituciones que ralentizaba el trabajo conjunto y que requería unos tiempos que eran difíciles de hacer confluir. Tampoco podemos obviar las diferencias en la cultural digital entre países e instituciones (ya hemos mencionado, por ejemplo, las dificultades técnicas de Radio Yúuyum), así como las disparidades económicas; ambos aspectos minaban en ocasiones las capacidades de participación de nuestros colaboradores.

El proyecto no solo tuvo que enfrentarse a las complejidades de la colaboración internacional, sino que también encontró diferencias distintivas entre el trabajo en un entorno museal y el trabajo que se realiza de una empresa de tecnología como Google (Arts \& Culture). En general, los plazos propuestos por el proyecto parecían demasiado largos para los financiadores. Por su parte, los colaboradores de Google Arts \& Culture desestimaron algunas de las investigaciones académicas y de contextualización que los curadores consideraban reveladoras e importantes, pues su enfoque estaba más en la generación de resultados llamativos (el 'output') y, por tanto, estaban más interesados en una narrativa cautivadora, basada en gran medida en imágenes o recursos visuales, que en una exposición más meticulosa; las dos partes tenían que comprometerse regularmente en términos de longitud del texto y detalle de la explicación, incluidos los metadatos. Estas discusiones en curso a veces enriquecieron el proyecto y permitieron el desarrollo de nuevas ideas (la réplica de la escalera o la inclusión de un viaje de Google Earth Voyager (Google Earth/Maudslay, s.f.)), pero también a veces se sintieron como un impedimento para los curadores en términos de trabajo académico y rigor. Igualmente, también fue necesario negociar el orden de aparición de los resultados en las páginas web, ya que cada una de las dos instituciones quería dar prioridad a sus colaboradores y a los contenidos que consideraba más importantes.

Aparte de las diferencias entre colaboradores, el Proyecto Google Maya también encontró dificultades concernientes a la difusión del proyecto, sobre todo entre uno de nuestros públicos prioritarios, la población local. Una de las principales funciones de un museo es la educación y divulgación de la cultura; con esto en mente los integrantes del proyecto pensamos que un proyecto digital contribuiría a acercar las colecciones de un modo universal (ver Hylland 2017), un fin que compartíamos con nuestro colaborador Google Arts \& 
Culture; sin embargo, una revisión autocrítica de nuestro trabajo nos hace reflexionar si, aunque pudimos contribuir a ello, este fin era totalmente posible.

A pesar de que la plataforma Google Arts \& Culture se basa en la idea de hacer que el arte y la cultura sean accesibles en todo el mundo -tal y cómo dice uno de los fundadores, Amit Sood, recordando su infancia en India (Sood, 2011)-, incluso en partes del mundo que de otra manera tienen poco o ningún acceso a parte de la información y los objetos exhibidos en los grandes museos, averiguamos que esta alta pretensión no se refleja en la realidad. Las páginas web de Google Arts \& Culture resultan bastante grandes y pesadas y, aunque tienen un modo para conexiones bajas y enfocado para el uso con dispositivos móviles (teléfonos inteligentes), lo cierto es que para poder utilizar todas las funciones se necesita acceso a internet y un equipo (sea computadora o teléfono móvil) hasta un cierto punto reciente. Por ejemplo, para la presentación del proyecto, las oportunidades de la plataforma de Google Arts \& Culture y los objetos Maudslay ya digitalizados a nuestros colaboradores guatemaltecos, llevábamos en nuestro viaje de 2017 unos Google Cardboard, lentes de realidad aumentada muy simples para el uso con un teléfono inteligente. Rápidamente nos dimos cuenta de que solo se podían usar estos Cardboard con un teléfono inteligente de más o menos alta calidad, o que al menos tuvieran unas especificaciones de las que carecían los móviles más populares de precio medio-bajo en Guatemala. Esto es ilustrativo de que, aunque obviamente la digitalización puede hacer a los museos y sus objetos más accesibles, todavía quedan muchas personas y comunidades que quedan excluidas de estas propuestas. En nuestro caso, encontramos diferentes iniciativas locales con bastante interés en colaborar, pero con limitaciones tanto a nivel tecnológico como económico que no les permitió participar como hubieran querido, ni nos permitió presentar los materiales tal como habíamos estado acostumbrados a hacerlo en la Ciudad de México o en Londres.

Por tanto, deberíamos preguntarnos si verdaderamente podemos decir que la digitalización de las colecciones de museos realmente promueve una 'democratización de la cultura', si no todo el mundo tiene acceso a estos contenidos. También deberíamos decir que las limitaciones técnicas de algunos de nuestros colaboradores, así como las dificultades por parte de Google Arts \& Culture para darles acceso a la plataforma, implicaron que en varias ocasiones la imagen que se proyectó de ellos y de sus actividades en las páginas web fue a partir de nuestras propias contribuciones como curadores del proyecto. El hecho de que fuéramos nosotros las que presentamos sus proyectos y no ellos silenció sus voces mientras nosotros hablábamos por ellos, ${ }^{5}$ lo que aumenta nuestro cuestionamiento acerca de si estos proyectos realmente consiguen una 'democratización del conocimiento'. Finalmente, creemos conveniente mencionar las dificultades que en ocasiones encontramos para conseguir un lenguaje inclusivo que se dirigiera y fuera útil a los distintos receptores de nuestra página, tanto académicos como los distintos componentes del público general. Sí

\footnotetext{
5 Un ejemplo sería el caso de Radio Yuúyum. El hecho de que fueran presentados en la página a través de una entrevista les dio cierta voz, pero su colaboración hubo de ser incluída en una de las exhibiciones en línea realizada por los curadores del Museo Británico, por lo que la presentación última se realizó a través de la narrativa de ellas. Otros colaboradores ni siquiera contaron con una entrevista para manifestar su propia voz.
} 
logramos, sin embargo, uno de nuestros objetivos, publicar las páginas tanto en inglés como en español.

Por último, consideramos que es necesario poner sobre la mesa una reflexión sobre los tiempos necesarios para llevar a cabo este tipo de proyectos. Un proyecto digital requiere una considerable financiación y la necesidad de fondos económicos implica que estos proyectos han de realizarse en un tiempo limitado. Esto indudablemente choca con los tiempos requeridos para un proyecto museístico y tiene serias consecuencias en la calidad y cantidad de resultados que es posible obtener. Igualmente, tiene repercusiones en las capacidades de los proyectos para promover colaboraciones.

Ya hablamos de los distintos tiempos institucionales que son difíciles de coordinar. La consecuencia de ello es que muchas veces nuestras colaboraciones fueran a nivel más personal que institucional y se desarrollaron a partir de nuestros contactos personales. Sería necesario preguntarse si muchas veces fueron realmente las mejores opciones que teníamos de colaboración o si otras veces fue necesario recurrir a las opciones con las que ya contábamos por falta de tiempo. Por ejemplo, en uno de últimos viajes a México conocimos un equipo que estaba haciendo trabajo de digitalización dentro de la CNCPC que, de haber tenido tiempo, podría haber resultado en una muy fructífera colaboración. También hay que considerar que los distintos intereses entre instituciones, así como sus posibilidades legales y sus dificultades para asumir riesgos derivados de la exposición de sus materiales en internet, complicaron el establecimiento de acuerdos institucionales a largo plazo. Todo ello tuvo sus consecuencias: la imposibilidad del Museo Británico de mantener tras la finalización del proyecto y del contrato laboral de sus curadores unas colaboraciones que había costado tanto establecer.

\section{Conclusiones finales}

Nuestra experiencia en el Proyecto Google Maya nos indica que no existe una conclusión simple o directa para un tema como la digitalización en los museos y el patrimonio. El proceso de reflexión post-proyecto todavía es un trabajo que estamos realizando, pero podríamos decir con confianza que las posibilidades de la curaduría digital y en línea ciertamente facilitan la colaboración internacional y el intercambio y co-creación de conocimiento. De hecho, la reciente pandemia del COVID-19 y sus consecuentes aislamientos sociales hacen de este un tiempo idóneo para plantearse la conveniencia de implantar este tipo de estrategias digitales en los museos.

Es importante recordar que la digitalización no es en sí misma un proyecto, sino simplemente una herramienta que se utiliza para crear datos que deben contextualizarse con (y contextualizar) el conocimiento existente; para ello, las iniciativas de digitalización deben estar conectadas o planificadas como proyectos de curaduría digital. Las plataformas digitales de los museos son una oportunidad para crear experiencias alternativas a las visitas físicas a los museos, complementándose ambas mutuamente, y por ello deberían ser algo más que una 
simple colección digitalizada. Sin embargo, el emprendimiento de una curaduría digital, a pesar de sus ventajas y beneficios, es una iniciativa que debe considerarse con cuidado, ya que no solo se necesita dinero, sino también mucho tiempo. Muy a menudo, en el patrimonio cultural, los profesionales buscan principalmente fuentes de financiación, lo cual es comprensible. Pero nuestro aprendizaje ha demostrado que el tiempo y la experiencia forman parte de un proyecto exitoso tanto como las finanzas (ver Abbott, 2008). Por ejemplo, es notable que nuestras colaboraciones aumentaron y fueron bastante más exitosas en cuanto a co-curaduría en México que en Guatemala, lo que se ve asimismo reflejado en las respectivas páginas web. A pesar de haber contado con financiamiento para ambas, no solo contamos con más tiempo para el proyecto en México (dos años para México, un año para Guatemala), sino que, además, al haberse realizado después, contábamos con más experiencia. Además, la experiencia del Proyecto Google Maya también parece indicar que para el buen transcurso de proyectos de curaduría digital y colaborativa sería necesario un impulso y revisión de legislaciones y estrategias institucionales que los faciliten.

También creemos necesaria una exposición más clara de los objetivos de las distintas instituciones y colectivos a la hora de negociar las colaboraciones antes de que estas comiencen. A pesar de las propuestas y discusiones detalladas sobre el proyecto antes de llegar a un acuerdo, quedó claro con bastante rapidez que las metas y objetivos de los dos colaboradores principales, el Museo Británico y Google Arts \& Culture, eran lo suficientemente dispares como para en ocasiones poner al proyecto en una posición incómoda y comprometerlo: no debía ser un proyecto de investigación académica, pero tampoco un proyecto más superficial y centrado en los medios. En retrospectiva, si se hubieran establecido límites más claros (de influencia y toma de decisiones), así como una separación y definición más específica de responsabilidades (en términos de carga de trabajo, planificación y procesamiento de contenido), se hubiera facilitado que el proyecto se desarrollara sin problemas, evitando frustraciones para ambos lados y simplificando algunas de las partes del proyecto; todo ello podría haber conducido a resultados más consistentes, coherentes y, sobre todo, de mayor calidad.

Uno de los aspectos que más frustración supusieron para el proyecto está relacionado con los diferentes objetivos temporales: como muchos otros museos, el Museo Británico se encuentra en el proceso de encontrar una solución para el almacenamiento y la conservación de grandes cantidades de datos digitales en diferentes formatos y necesita desarrollar una buena estrategia para garantizar que estos datos se almacenen de forma segura y sean accesibles durante largos periodos de tiempo. Por esto, el proyecto esperaba utilizar las plataformas que Google ponía a nuestro alcance como forma de almacenamiento temporal. En la mente de los curadores, este concepto 'temporal' suele significar varios años, por lo que el cierre de varias plataformas y herramientas (por ejemplo, Google Poly y Expeditions cerraron el 30 de junio de 2021) después de apenas un par de años de existencia crea problemas en términos de accesibilidad e investigación. Hay que decir que el contenido ('output') que creó el proyecto seguirá estando disponible, pero con diferentes URL, opciones de búsqueda distintas e incluso diversas formas de acceder a él. 
Los distintos aspectos tratados a lo largo de este texto (así como otros que no tuvimos oportunidad de presentar) nos llevan a confiar en la viabilidad y conveniencia de los proyectos de curaduría digital multicolaborativos. Empero, tal y como hemos expuesto, creemos que hay aspectos que convendría revisar para poder sacar el máximo partido de este tipo de proyectos, tanto a nivel legislativo como a nivel institucional y en la planeación de los propios proyectos. Esperamos que la experiencia del Proyecto Google Maya pueda contribuir a la discusión sobre cuál es la mejor manera de emprender este tipo de proyectos que, según parece indicar el camino que la museología está tomando recientemente, serán cada vez más frecuentes.

\section{Referencias}

ABBOTT, D. (2008). "What is Digital Curation" en DCC Briefing Papers: Introduction to Curation. Edinburgh: Digital Curation Centre. <https://www.dcc.ac.uk/guidance/briefingpapers/introduction-curation/what-digital-curation> [Consulta: 28 de febrero de 2021]

BM-Arc at THE BRITISH MUSEUM (s.f.). British Museum Archaeological Research Collection. $<$ https://www.britishmuseum.org/our-work/national/bm-arc> [Consulta: 27 de febrero 2021]

GARVIN, K. M. (2019). "Reclaiming Our Domain: Digitization of Museum Collections and Copyright Overreach" en Idea-The Law Review of the Franklin Price Center for Intellectual Property, vol. $59, \mathrm{n}^{\circ} 2, \mathrm{p} .455-481$.

GODMAN, F. D. y SALVIN, O. (1879-1915). Biologia centrali-americana, or, Contributions to the knowledge of the fauna and flora of Mexico and Central America. Londres: R.H. Porter.

GOOGLE EARTH/MAUDSLAY (s.f.). Maya Ruins with Alfred Maudslay. $<$ https://earth.google.com/web/data=CjASLhIgZGE0NjZiN2RIMTJIMTFIOGJmMTIxNWJiNDV kZTkwZTEiCnZveV9zcGxhc2g?EarthFeedSuffix=ttgac $>$ [Consulta: 27 de febrero 2021]

GOOGLE MAYA PROJECT (2017). Preserving Maya Heritage; A glimpse into the research and technological preservation of Maya heritage / Conservación del patrimonio maya; Un vistazo al estudio y la conservación digital de la herencia maya. $<$ https://artsandculture.google.com/project/preserving-maya-heritage $>$ [Consulta: 26 de febrero de 2021]

GOOGLE MAYA PROJECT (2019). Exploring the Maya World; A journey into the past with ancient art and digital technology / Explora el mundo de los mayas; Un viaje al pasado a través del arte antiguo y tecnología digital. <https://artsandculture.google.com/project/exploring-the-mayaworld $>$ [Consulta: 26 de febrero de 2021]

GRAHAM, I. (2002). Alfred Maudslay and the Maya: A Biography. Londres: The British Museum Press.

HERBERT PESQUERA, L.de L., CUEVAS GARCÍA, M., ZEHRT, C., y SOMOHANO ERES, A. (en prensa). "Una réplica de la Escalera Jeroglífica del Palacio de Palenque como alternativa para su conservación". Ponencia presentada en Encuentro sobre evaluación de criterios de intervención en materiales pétreos (INAH, UNAM, CNCPC), Ciudad de México, 19.-21.11.2019, en proceso de publicación.

HYLLAND, O. M. (2017). "Even better than the real thing? Digital copies and digital museums in a digital cultural policy" en Culture Unbound, Vol. 9 (1), pp.62-84. $<$ https://doi.org/10.3384/cu.2000.1525.1791> [Consulta: 28 de febrero de 2021]

LYNCH, B. (2001). "If the Museum is the Gateway, who is the Gatekeeper?" en Engage, Winter 2001, Issue 11, p. 1-12. 
MATHEWS, P. (1999). "Pilot Study of the Maudslay Casts in the British Museum, 1998" en Famsi. $<$ http://www.famsi.org/reports/97082/> [Consulta: 26 de febrero de 2021].

MAUDSLAY, A. P. (1889-1902). “Archaeology” en Godman, F. D. y Salvin, O. Biologia centraliamericana, or, Contributions to the knowledge of the fauna and flora of Mexico and Central America. Londres: R.H. Porter.

PAGEL, J. (2015). "El museo y los derechos de autor en Europa; una encuesta y unas recomendaciones" en PH: Boletín del Instituto Andaluz de Patrimonio Histórico, Año n²3, nº8, p.36-40.

SÁNCHEZ GAMBOA, A. A. et al (2020). "The Hieroglyphic Stairway of House C, Palenque, Chiapas: New Approaches” en Mexicon, vol. XLII, n.1, p.7-11.

SÁNCHEZ Y POLYUKHOVICH (s.f.). Stairway to Heaven / Escalera al cielo. $<$ https://g.co/arts/pJhf1hWcHJtB93G16> [Consulta: 27 de febrero 2021]

SCHÖTZ, G. J. (2020). "Los derechos de los artistas, de los museos y del público: necesidad de armonización” en Revista La Propiedad Inmaterial, n²9, p.137-181.

SOMOHANO ERES Y ZEHRT (s.f.). Yucatan Today / Yucatán en los tiempos que corren. $<$ https://g.co/arts/XRenvSoLoAvHnrSt8> [Consulta: 28 de febrero 2021]

SOOD, A. (2011). "Building a museum of museums on the web". TED, ideas worth spreading $<$ https://www.ted.com/talks/amit sood building a museum of museums on the web?utm ca mpaign=tedspread\&utm_medium $=$ referral\&utm_source $=$ tedcomshare $>\left[{ }_{\text {Consulta: }}^{-} 16\right.$ de febrero de 2021] 